\title{
PENGARUH BRAND IMAGE TERHADAP IMPLEMENTASI DESAIN INTERIOR STUDI KASUS MUSEUM BASKET THE BUCKETLIST, BOGOR
}

\author{
Maitri Widya Mutiara', Ardya Kristina ${ }^{2}$ \\ ${ }^{1}$ Desain Interior, Universitas Tarumanagara \\ Email: maitrim@fsrd.untar.ac.id \\ ${ }^{2}$ Desain Interior, Universitas Tarumanagara \\ Email: ardyakristina47@gmail.com
}

Masuk : 20-04-2020, revisi: 29-04-2020, diterima untuk diterbitkan : 30-04-2020

\begin{abstract}
Brand image is a representation of the whole brand and is formed from information and past experience of the brand. Implementation of brand image in interior design will provide a positive image. The museum is an institution that has properties, one of which is Basketball is a popular sport in Indonesia. But unfortunately, the history of basketball development in Indonesia has not been well documented. The Bucketlist is a place as a basketball history museum in Indonesia. Research methods to support the results of the design carried out in this paper are literature studies, site studies /floor plans and focus group discussions. This research is the basis for making design decisions on the Interior design of The Bucketlist Basketball Museum. In order to attract visitors, a strong brand image is needed. Brand image is a representation of the overall perception of the brand and is formed from information and past experience of the brand. Servicescape itself is a physical environment which includes services in an interior or exterior facility. Awareness of this servicescape will affect users and visitors of the place. Based on the FGD that has been done, The Bucketlist's brand image is basketball-focused, experience-oriented, instagrammable, and family friendly. The brand image that has been determined from the results of this discussion becomes the basis for the formation of the image of the space to be applied in the interior design of The Bucketlist Basket Museum. In its application, all four aspects of the brand image have been applied but there is still room for maximization given the current project is still running.
\end{abstract}

Keywords: interior, brand image, servicescapes, Museum Basket

\begin{abstract}
ABSTRAK
Perancangan interior yang baik memiliki banyak pertimbangan yang akan membuat nyaman penggunanya. Sehingga pengguna adalah sebagai salah satu pertimbangan dalam perancangan. Dalam ruang publik, selain pengguna juga perlu mempertimbangkan citra ruang tersebut yang sesuai dengan citra brand yang dapat dilihat melalui brand image. Brand image merupakan representasi dari keseluruhan merek dan dibentuk dari informasi dan pengalaman masa lalu terhadap merek tersebut. Implementasi brand image dalam desain interior akan memberikan citra yang positif. Museum merupakan lembaga yang memiliki sifat, salah satunya adalah Basket merupakan olahraga yang digemari di Indonesia. Akan tetapi, sejarah perkembangan basket di Indonesia belum terdokumentasikan dengan baik. The Bucketlist hadir menjadi wadah sebagai museum sejarah basket di Indonesia. Dalam rangka menarik pengunjung, diperlukan brand image yang kuat. Brand image adalah representasi dari keseluruhan persepsi terhadap merek dan dibentuk dari informasi dan pengalaman masa lalu terhadap merek itu. Servicescape sendiri merupakan lingkungan fisik yang di dalamnya mencakup pelayanan pada suatu fasilitas interior ataupun eksterior. Kesadaran akan servicescape ini akan mempengaruhi pengguna maupun pengunjung tempat tersebut. Metode penelitian untuk mendukung hasil desain yang dilakukan dalam penulisan ini adalah studi literatur, studi tapak/denah dan diskusi kelompok terarah (FGD). Penelitian ini menjadi dasar pengambilan keputusan-keputusan desain pada desain Interior Museum Basket The Bucketlist. Hasil penelitian ditemukan bahwa, brand image The Bucketlist adalah basket-focused, experience-oriented, instagrammable, dan family friendly. Brand image yang sudah ditetapkan dari hasil diskusi ini menjadi dasar bagi pembentukan citra ruang yang ingin diterapkan dalam desain interior Museum Basket The Bucketlist. Dalam penerapannya, keempat segi brand image sudah diterapkan namun masih terbuka ruang untuk dimaksimalkan mengingat saat ini proyek masih berjalan.
\end{abstract}

Kata Kunci: interior, brand image, servicescapes, Museum Basket 


\section{PENDAHULUAN}

\section{Latar Belakang}

Basket merupakan olahraga yang memiliki banyak penggemar di Indonesia, mulai dari anakanak hingga dewasa. Perkembangan olahraga basket di Indonesia melalui perjalanan yang panjang. Berawal dari orang Tionghoa yang membawa permainan basket pertama kali ke Indonesia, hingga munculnya lembaga PERBASI pada tahun 1951 yang menaungi olahraga basket secara resmi. Meskipun demikian, dokumentasi data ataupun benda bersejarah yang berkaitan dengan perkembangan basket di Indonesia belum tersusun dengan rapi dan baik. Oleh karena itu, pembangunan Museum Basket The Bucketlist menjadi salah satu wadah pendokumentasian perkembangan basket di Indonesia yang baik. Dalam rangka menjadi museum yang baik dan menarik, maka The Bucketlist harus memiliki brand image yang baik secara menyeluruh termasuk implementasi pada interior museum.

Menurut hasil pertemuan pada International Council of Museums ke-11 di Kopenhagen, museum adalah sebuah lembaga yang bersifat tetap, tidak mencari keuntungan, melayani masyarakat dan perkembangannya, terbuka untuk umum, memperoleh, merawat, menghubungkan dan memamerkan artefak-artefak perihal jati diri manusia dan lingkungannya untuk tujuan studi, pendidikan dan rekreasi (Direktorat Museum, 2008). Berdasarkan Peraturan Pemerintah RI No. 19 tahun 1995, museum memiliki tugas menyimpan, merawat, mengamankan, dan memanfaatkan koleksi museum berupa benda cagar budaya. Oleh karena itu, museum memiliki dua fungsi besar yaitu sebagai tempat pelestarian dan sumber informasi benda budaya dan alam. Sementara basket adalah permainan beregu yang dimainkan oleh dua regu baik putra maupun putri yang masing-masing regu terdiri dari lima orang pemain. Permainan dimainkan di lapangan berbentuk persegi panjang dengan ukuran tertentu yang bertujuan memasukkan bola ke arah keranjang lawan dan menahan lawan agar tidak memasukkan bola

Brand image sendiri adalah representasi dari keseluruhan persepsi terhadap merek dan dibentuk dari informasi dan pengalaman masa lalu terhadap merek itu. Citra terhadap merek berhubungan dengan sikap yang berupa keyakinan dan preferensi terhadap suatu merek. Konsumen yang memiliki citra yang positif terhadap suatu merek, akan lebih memungkinkan untuk melakukan pembelian (Setiadi, 2003). Brand image terdiri dari komponen-komponen, diantaranya: Atribut, Keuntungan, Sikap Merek. Atribut merupakan pendefinisian deskriptif tentang fitur-fitur yang ada dalam produk atau jasa. Keuntungan merupakan nilai personal yang dikaitkan oleh konsumen pada atribut produk atau jasa tersebut. Sementara itu Sikap Merek didefinisikan sebagai evaluasi keseluruhan atas suatu merek, apa yang dipercayai oleh konsumen mengenai merek-merek tertentu sejauh apa konsumen percaya bahwa produk atau jasa tersebut memiliki atribut atau keuntungan tertentu, dan penilaian evaluatif terhadap kepercayaan tersebut bagaimana baik atau buruknya suatu produk jika memiliki atribut atau keuntungan tersebut.

Kertajaya (2007) menyebutkan bahwa brand image di benak konsumen dapat dipengaruhi oleh beberapa faktor, antara lain:

a. Komunikasi dari sumber lain yang belum tentu sama dengan yang dilakukan pemasar. Komunikasi bisa datang dari konsumen lain, pengecer dan pesaing.

b. Pengalaman konsumen melalui suatu eksperimen yang dilakukan konsumen dapat mengubah persepsi yang dimiliki sebelumnya. Oleh sebab itu, jumlah berbagai persepsi yang timbul itulah yang akan membentuk total image of brand (citra keseluruhan sebuah merek).

c. Pengembangan produk: posisi brand terhadap produk memang cukup unik. Di satu sisi, 
merupakan payung bagi produk, artinya dengan dibekali brand tersebut, produk dapat naik nilainya. Di sisi lain, performa ikut membentuk brand image yang memayunginya dan tentunya konsumen akan membandingkan antara performa produk yang telah dirasakan dengan janji brand dalam slogan. Selain brand image, service escape juga memiliki hubungan terhadap implementasi desain.

Menurut Bitner (1992), service escape adalah lingkungan fisik yang di dalamnya mencakup pelayanan pada suatu fasilitas interior ataupun eksterior. Pelayanannya tersebut meliputi penilaian terhadap interior desain, desain eksterior, simbol, tempat parkir, peralatan yang disediakan, denah layout, kualitas udara ataupun suhu udara yang ada pada fasilitas tersebut.

Elemen servicescape menurut Bitner (1992) adalah sebagai berikut

Tabel 3.1. Elemen dari servicescape

\begin{tabular}{|c|l|l|l|}
\hline $\begin{array}{l}\text { Service } \\
\text { escape }\end{array}$ & \multicolumn{1}{|c|}{ Elemen } & \multicolumn{2}{|c|}{ Atribut } \\
\hline AC & $\begin{array}{l}\text { Kondisi lingkungan } \\
\text { sekitar } \\
\text { Ambience condition) }\end{array}$ & $\begin{array}{l}\text { Noise } \\
\text { Music } \\
\text { Odor }\end{array}$ & $\begin{array}{l}\text { Temperature } \\
\text { Air quality }\end{array}$ \\
\hline SLF & $\begin{array}{l}\text { Ruang, denah, dan } \\
\text { fungsi (Space, } \\
\text { ayout, and function) }\end{array}$ & Furnishing & $\begin{array}{l}\text { Layout } \\
\text { Equipment }\end{array}$ \\
\hline SSA & $\begin{array}{l}\text { Penunjuk, simbol, dan } \\
\text { benda artefak (Signs, } \\
\text { symbols, and artifact) }\end{array}$ & $\begin{array}{l}\text { Style of décor } \\
\text { Personal artifact }\end{array}$ & $\begin{array}{l}\text { Signage } \\
\text { Etc }\end{array}$ \\
\hline
\end{tabular}

a. Kondisi dari lingkungan

Manusia dapat memikirkan serta merespons pelayanan suatu tempat tergantung pada kondisi lingkungannya seperti temperatur, pencahayaan, kebisingan, kualitas udara, musik, dan warna.

b. Ruang, denah, dan fungsinya

Ruang, denah, dan fungsinya mempengaruhi tingkah laku bekerja karyawan dan tingkah laku pengunjung pada suatu area,

c. Petunjuk, simbol, dan benda artefak

Elemen simbol ini dirasakan penting untuk membantu pengunjung atau karyawan dalam mengkategorikan ruangan serta mengkomunikasikan secara simbolis. Dalam beberapa perusahaan, beberapa benda penting akan diletakkan di bagian yang paling terihat, karena perusahaan ingin mengenalkan filosofi yang mereka yakini.

Dari jurnal services marketing oleh Wakefield dan Blodgett (1994), alasan tepat dalam penerapan servicescape adalah:

a. Kepuasan di dalam servicescape mempunyai dampak positif terhadap jangka waktu yang akan dihabiskan di tempat tersebut.

b. Kepuasan dengan keadaan servicescape dapat berdampak positif terhadap keinginan untuk kembalinya seseorang ke tempat tersebut.

c. Akses yang mudah dan user-friendly pada denah juga dapat membawa pengaruh yang positif terhadap pengunjungnya. 
d. Bisa mendapatkan perhatian lebih banyak dari pengunjung bila terjadi rotasi dekorasi ataupun suasana untuk menambah daya tarik.

Servicescape memiliki pengaruh terhadap perilaku pelanggan. Pelanggan dan karyawan dapat merespon lingkungan fisik secara level emosional, kognitif, dan psikologis terhadap tingkah laku kebiasaan mereka, seperti dalam Zeithaml \& Bitner (1994). Respon tersebut meliputi lingkungan dengan kesadaran, emosi, psikologi, dan ragam respon dari setiap individu. Kesadaran akan servicescape akan berdampak pada seseorang hanya dengan merasakan dan melihat orang yang berdatangan serta barang yang dijual pada tempat tersebut.

Dalam perancangan interior, sebagai desainer perlu mempertimbangkan hal-hal terkait kebutuhan pengguna. Museum Basket The Bucketlist merupakan fasilitas komersial yang dibangun dengan tujuan tertentu, dengan visi-misi tertentu, dengan citra tertentu yang ingin diperlihatkan kepada pengguna yang datang. Sehingga sebagai desainer perlu mempertimbangkan citra-citra tersebut melalui wawancara dengan pemilik, melakukan diskusi terhadap pencinta basket, dan komunitas-komunitas terkait. Penelitian ini bertujuan untuk mendapatkan kata-kata kunci yang nantinya sebagai dasar penciptaan suasana ruang.

\section{METODE PENELITIAN}

Metode penelitian yang dilakukan dalam menganalisa pengaruh branding terhadap implementasi desain interior Museum Basket The Bucketlist adalah: dengan studi literatur, studi tapak/denah, Focus Group Discussion. Metode penelitian sebagai bagian dari proses desain yang digunakan untuk mendukung mendapatkan data-data terkait perencanaan desain dan juga untuk data pemilik serta pengguna/pengunjung yang akan datang ke Museum Basket The Bucketlist. Studi literatur adalah proses penelaahan terhadap semua teori-teori, baik yang terbit maupun tidak terbit, mengenai proyek yang berkaitan sehingga dapat menambah wawasan dan gambaran serta membantu saat melakukan analisa. Studi tapak/denah adalah proses pemahaman dan pembelajaran denah arsitektural secara penuh. Hal ini bertujuan agar interior mampu dirancang dengan sebaik mungkin. Selain itu Focus Group Discussion bertujuan untuk menampung dan mendiskusikan seluruh ide dan masukan dari berbagai pakar di bidangnya sehingga bisa menghasilkan desain yang maksimal dan berhasil. Peserta pada FGD ini adalah: pemilik, pemain basket professional, perwakilan dari komunitas pencinta basket, influencer di bidang olahraga, serta konsultan branding The Bucketlist.

\section{HASIL DAN PEMBAHASAN}

\section{Branding The Bucketlist}

Berdasarkan FGD yang telah dilakukan 2 kali oleh owner, branding agency, dan orang-orang yang datang dari kalangan influencer dan komunitas pecinta basket maka dapat disimpulkan bahwa brand image The Bucketlist adalah: basket-focused, experience-oriented, instagrammable, dan family friendly. Dalam implementasi desain, basket-focused bisa dicapai dengan pembentukan suasana tempat yang berhubungan dengan olah raga basket seperti locker room, lapangan, dsb. Selain itu, implementasi juga dapat mengambil inspirasi dari benda yang berhubungan seperti kotak sepatu, sneakers, bola, dan lain-lain. Segi experience-oriented dapat diaplikasikan melalui jalur sirkulasi yang satu arah agar pengunjung bisa memahami alur cerita yang ingin disampaikan, serta penggunaan teknologi interaktif agar terjadi interaksi dua arah yang dapat memberi pengalaman menarik kepada pengunjung. Segi instagrammable bisa didapat melalui penerapan elemen interior lantai, dinding, plafon serta furniture yang unik dan tidak biasa sehingga mampu menambah daya tarik pengunjung. Sementara segi family friendly bisa dicapai melalui adanya area khusus untuk anak-anak di luar area museum agar anak-anak 
juga dapat menikmati ketika berkunjung ke The Bucketlist. Selain itu, segi family friendly bisa dicapai dengan penggunaan material yang aman untuk anak dan furniture dengan sisi yang tidak tajam.

\section{Desain Museum}

Saat ini proyek masih sedang berjalan sehingga desain terlampir bukanlah desain final dari museum karena masih terbuka ruang untuk berubah apabila dibutuhkan. Desain terlampir adalah update terakhir versi 2 Desember 2019.

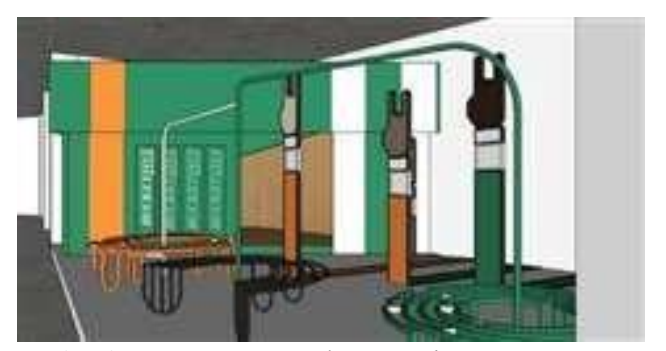

Gambar 1. Area tunggu dan ticketing museum (Sumber: PT. Gagasreka Urbanarsitektura)

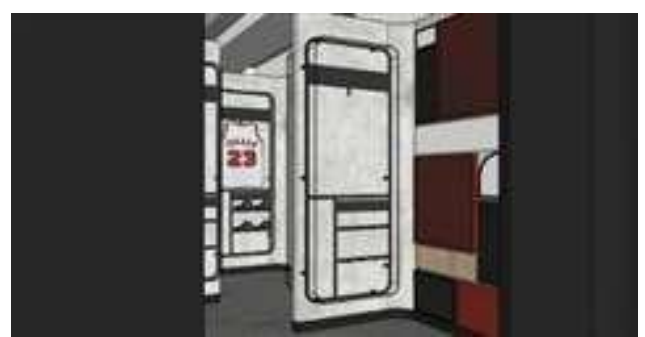

Gambar 2. Area memorabilia kostum basket 1 (Sumber: PT. Gagasreka Urbanarsitektura)

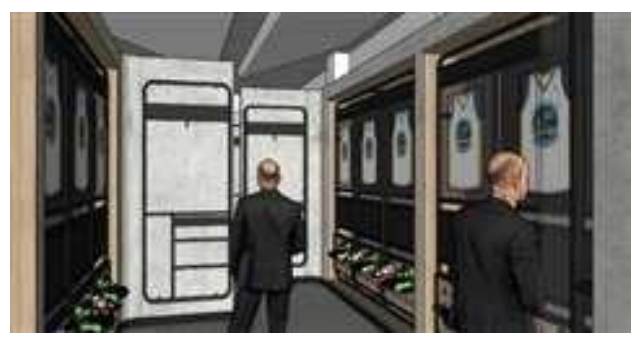

Gambar 3. Area memorabilia kostum basket 2 (Sumber: PT. Gagasreka Urbanarsitektura)

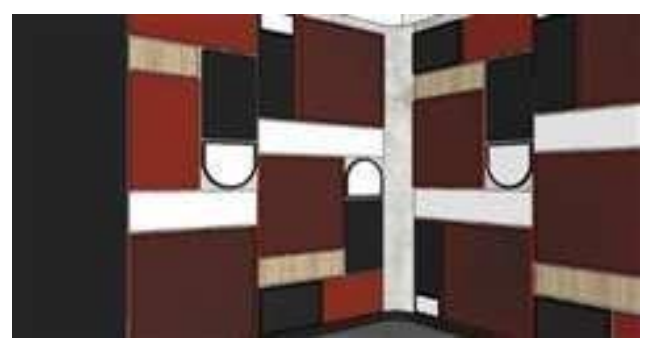

Gambar 4. Spot foto

(Sumber: PT. Gagasreka Urbanarsitektura) 


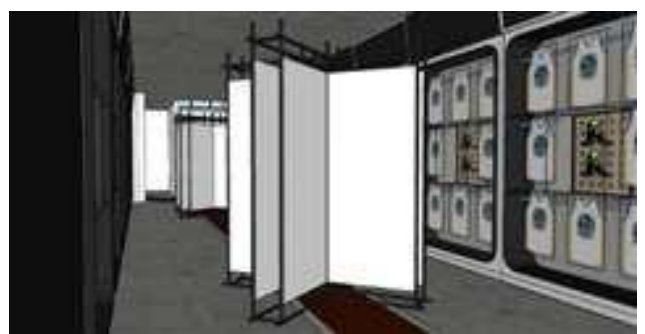

Gambar 5. Area memorabilia kostum basket 3

(Sumber: PT. Gagasreka Urbanarsitektura)

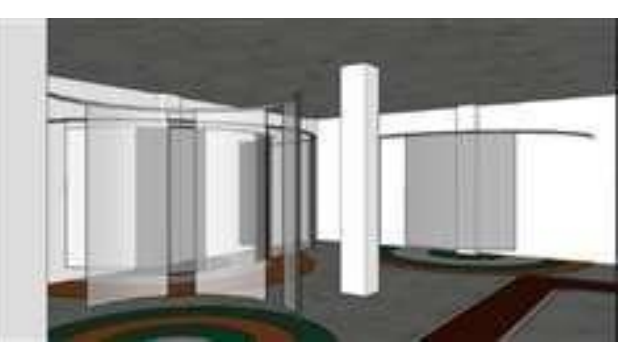

Gambar 6. Area penjelasan basket (Sumber: PT. Gagasreka Urbanarsitektura)

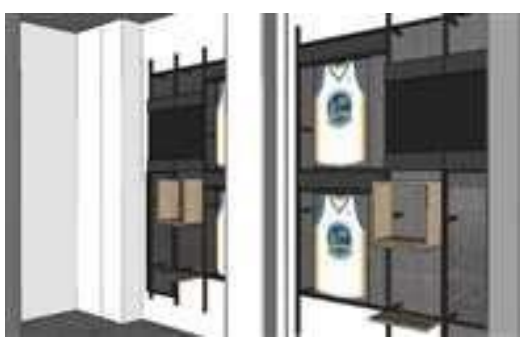

Gambar 7. Area memorabilia kostum basket 4

(Sumber: PT. Gagasreka Urbanarsitektura)

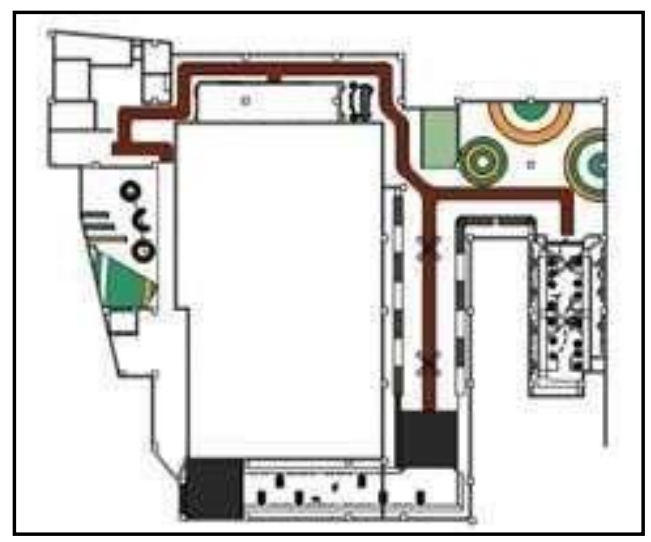

Gambar 8. Denah museum

(Sumber: PT. Gagasreka Urbanarsitektur 


\section{Analisis Implementasi Brand Image pada Desain Museum \\ Basket-Focused}

Basket-Focused ditampilkan melalui penggunaan kotak sepatu sebagai inspirasi implementasi desain museum di salah satu area di museum. Selain itu, konten dari museum sendiri merupakan barang-barang yang dekat dengan olahraga basket seperti sepatu, baju basket, dan lain lain, maka bentuk panel pun harus disesuaikan dengan bentuk barang pajangannya. Adapun bentuk implementasi dapat dilihat pada gambar yang dilingkari di bawah ini:

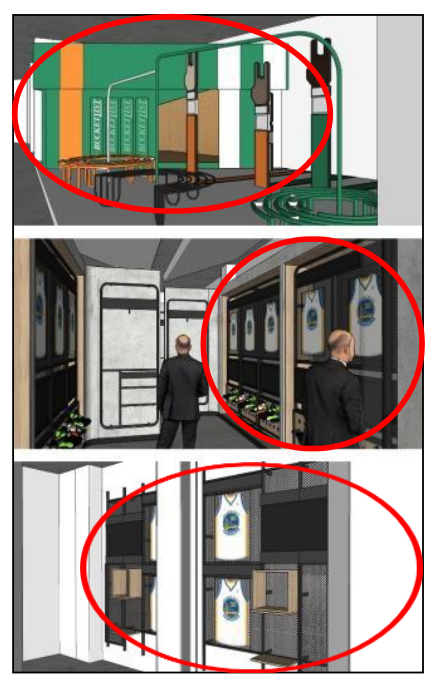

Gambar 9. Implementasi segi basket-focused pada desain museum Sumber: Ardya Kristina, 2019

\section{Experience-Oriented}

Berdasarkan apa yang sudah dijelaskan pada poin tentang segi experience-oriented, dapat dilihat bahwa museum belum benar-benar menampilkan desain yang mendukung terciptanya museum yang experience- oriented. Secara umum, desain museum sudah menampilkan sirkulasi yang satu arah agar pengunjung bisa memahami dan mengerti alur cerita yang ingin disampaikan. Ada satu area yang memiliki sirkulasi dua arah. Hal ini dikarenakan bentuk bangunan arsitektural. Dari segi teknologi, desain museum sejauh ini belum menampilkan penggunaan teknologi tersebut. Namun karena kini proyek masih dalam proses, maka masih terbuka ruang untuk ditambahkan penggunaan teknologi pada museum.

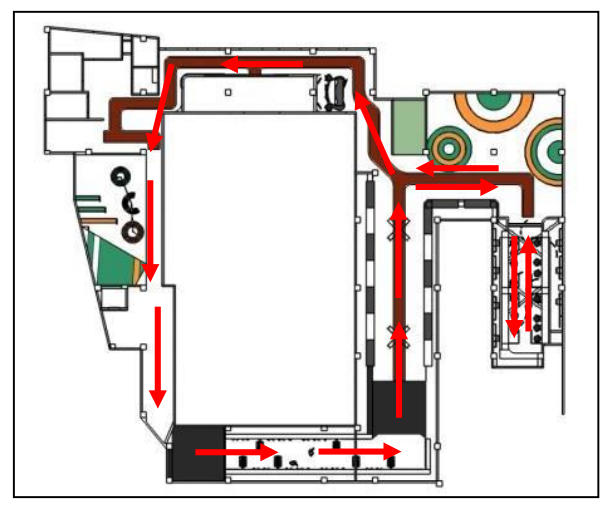

Gambar 10. Alur sirkulasi pada museum Sumber: Ardya Kristina, 2019 


\section{Instagrammable}

Berdasarkan apa yang sudah dijelaskan pada poin tentang segi instagrammable, maka dapat dilihat bahwa desain museum sudah menampilkannya. Hal ini terlihat adanya bagian-bagian museum dengan bentuk elemen interior yang unik dan menarik.

Penggunaan kotak sepatu sebagai inspirasi dari bagian museum bisa dibilang merupakan sesuatu yang tidak biasa. Selain itu, bentuk kursi yang tidak biasa dengan warna yang eksentrik juga menambah daya tarik. Bagian lain museum yaitu dinding dengan finishing panel kombinasi merah dan hitam juga bisa dibilang menambah daya tarik. Hal ini dikarenakan pemilihan warna yang kontras serta pemilihan dan pengaturan bentuk sehingga tercipta pola pada dindingnya.

Adapun penerapan segi instagrammable bisa dilihat pada gambar dibawah:

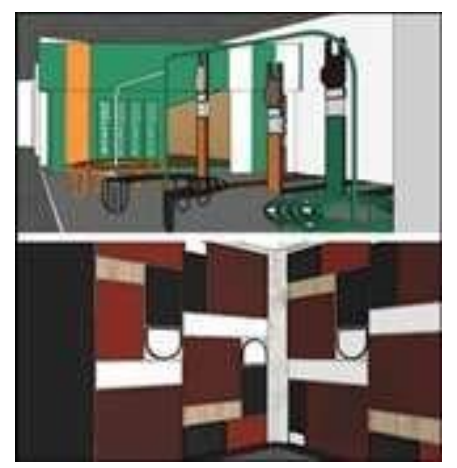

Gambar 11. Bagian museum yang instagrammable Sumber: Ardya Kristina, 2019

\section{Family Friendly}

Segi family friendly sudah terlihat melalui bentuk-bentuk panel yang tidak memiliki sudut-sudut yang tajam. Selain itu, penggunaan edging juga diutamakan pada sisi ketebalan furnitur agar tidak tajam. Namun, untuk area khusus untuk anak-anak tidak terletak pada area pamer museum. Bentuk furnitur yang family friendly tersebut bisa dilihat pada gambar di bawah ini: 


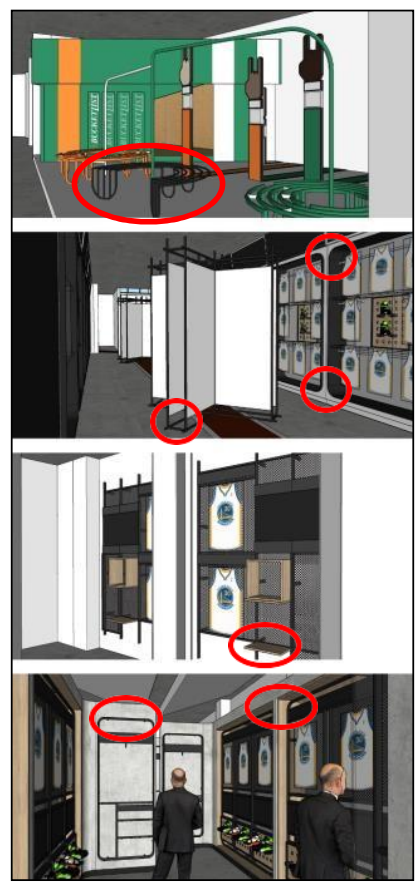

Gambar 12. Bagian furniture museum yang family friendly

Sumber: Ardya Kristina, 2019

\section{Analisis Hubungan Brand Image dengan Servicescape pada Museum}

Ruang, denah, dan fungsi (SLF) merupakan salah satu elemen pada servicescape. Ruang museum yang didesain dengan baik akan memaksimalkan tingkah laku pengunjung yang datang. Selain itu, penunjuk, simbol, dan artefak (SSA) juga merupakan elemen servicescape yang berperan penting dalam meningkatkan kepuasan pengunjung. SSA ditampilkan melalui gaya dekor museum yang tematik sehingga dapat menambah experience pengunjung yang datang. Brand image museum harus mampu memenuhi kebutuhan servicescape museum agar kepuasan pengunjung dapat maksimal.

\section{KESIMPULAN DAN SARAN}

Penelitian yang dilakukan oleh tim desain sebagai bagian dari proses perencanaan interior ruang Museum Basket The Bucketlist, meliputi studi literatur, studi tapak, dan Focus Group Discussion, telah menghasilkan 4 (empat) kata kunci Brand Image yaitu: Basket-focused, experienced oriented, instagrammable, dan family friendly. 4 (empat) kata kunci ini akan membantu tim desain interior mengambil keputusan untuk menciptakan ruang yang mencerminkan citra tersebut. Di antaranya adalah rencana ruang dan fungsi serta sirkulasi yang di desain akan mempengaruhi tingkah laku pengunjung yang datang. Selain itu keputusan terhadap pemilihan bentuk, warna dan tekstur serta pemilihan material juga akan berdampak pada citra yang ingin ditampilkan.

Secara umum, desain museum The Bucketlist sudah memenuhi brand image yang sudah direncanakan tetapi tidak dapat dipungkiri bahwa masih ada ruang agar segi experience-oriented dapat dimaksimalkan. Sebagai contoh, penggunaan teknologi sebaiknya diperbanyak karena masa kini manusia tidak bisa lepas dengan dunia digital. Selain itu, sirkulasi dapat diatur sedemikian rupa agar pengunjung benar-benar mengerti alur cerita yang ingin disampaikan.

\section{Ucapan Terima Kasih (Acknowledgement)}

Ucapan terima kasih kami kepada PT. Gagasreka Urbanarsitektura selaku pemberi kesempatan 
kerja praktek serta pak David Sian Reynaldo selaku Pembina kepada saudari Ardya Kristina. Kepada pemilik Museum Basket The Bucketlist; Mario Gerungan, Ali Budimansyah, Novabella selaku pemain basket professional; Irril, Belen, dan Teki selaku perwakilan dari komunitas pecinta basket; Kemal Palevi selaku influencer di bidang olahraga; dan Studio Skato yang merupakan konsultan branding the Bucketlist.

\section{REFERENSI}

Bitner, M.J. (1992). Servicescapes: The impact of physical surroundings on customers and $\begin{array}{llll}\text { employees. } \quad \text { Journal } & \text { 5 }\end{array}$ https://doi.org/10.1177/002224299205600205

Direktorat Museum. (2008). Pedoman museum Indonesia. Jakarta: Departemen Kebudayaan dan Pariwisata.

Kertajaya, Hermawan. (2007). Positioning, differensiasi, dan brand. Jakarta: Gramedia Pustaka Utama.

Setiadi, N. J., (2003) Perilaku konsumen: Konsep dan implikasi untuk strategi dan penelitian pemasaran. Jakarta: Prenada Media.

Wakefield, K.L., \& Blodgett, J. (1994). The importance of servicescapes in leisure service settings. Journal of Services Marketing, 8(3), 66-76. https://doi.org/10.1108/08876049410065624 